\title{
Ending Enclosure by Copying the Commons
}

\author{
Mita Williams \\ Leddy Library \\ University of Windsor
}

\section{Correspondence:}

Mita Williams

Leddy Library, University of Windsor

Windsor, Ontario, Canada

Email: mita [at] uwindsor.ca

\begin{abstract}
In the beginning (of bibliometrics), citation counts of academic research were generated to be used in annual calculations to express a research journal's impact. Now those same citation counts make up a social graph of scholarly communication that is used to measure the research strengths of authors, the hotness of their papers, the topic prominence of their disciplines, and assess the strength of the institutions where they are employed. More troubling, the publishers of this emerging social graph are in the process of enclosing scholarship by trying to exclude the infrastructure of libraries and other independent, non-profit organizations invested in research.

This paper will outline efforts currently being employed by scholarly communication librarians using platforms built by organizations such as Our Research's UnPaywall and Wikimedia's Wikidata Project so that the commons of scholarship can remain open. Strategies will be shared so that researchers can adapt their workflows so that they might allow their work to be copied, shared, and be found by readers widely across the commons. Scholars will be asked to make good choices.
\end{abstract}

Keywords: open access, scholarship, Creative Commons, enclosure 


\section{Introduction}

That which computation sets out to map and model it eventually takes over. Google sets out to index all human knowledge and becomes the source and the arbiter of that knowledge: it became what people think. Facebook set out to map the connections between people — the social graph—and became the platform for those connections, irrevocably reshaping societal relationships. Like an air control system mistaking a flock of birds for a fleet of bombers, software is unable to distinguish between the model of the world and reality-and, once conditioned, neither are we. (Bridle, 2018, p. 39)

This paper is in three parts. The first part will be dedicated to bringing the reader up to speed with recent developments of the major scholarly publishers that threaten to shut libraries out from the ecosystem of scholarship. The second part of the paper will be dedicated to strategies that are currently being employed by scholarly communication librarians and non-profit research-supporting bodies to resist the enclosure of scholarship. The third part of the paper will set out pathways for scholars and make clear what the consequences they set in motion when they decide where and how they will publish their research.

\section{Environmental Scan of Academic Publishing}

I will begin with a brief environmental scan of the current scholarly publishing landscape. To do so, I direct the reader to the research and the visualizations of scholarly workflows of the Innovations in Scholarly Communications Project (Kramer \& Bosman, 2016). From their visualizations it should become readily apparent to the reader that the entire process-from preprint servers to manuscript submission platforms to journal publication to research impact assessment-has been both horizontally and vertically integrated by for-profit publishing (Posada \& Chen, 2018).

I have stated that these for-profit publishers are enclosing scholarship, and I am cognizant of the gravity of this claim. I will back up this assertion by drawing attention to some of the current conditions that lead me to this conclusion. First, I must mention the recently announced GetFTR project—backed by the American Chemical Society, Elsevier, Springer Nature, Taylor \& Francis, and Wiley-that promises seamless access to full text of research and in doing so, holds the possibility to exclude options to find open access pre-print and post-print versions (Schonfeld, 2019). I also direct attention to the selective enforcement of copyright by the Big Five Publishers that allows research to be freely syndicated on ResearchGate (Hinchliffe, 2019) while withholding and regulating the right to the share the same works on course reading and learning management platforms (Elsevier, n.d.).

But the most important message that I would like to convey is that the citation graph is under threat of enclosure (Price, n.d.). The refusal of Elsevier, IEEE, and the American Chemical Society to allow their citations to become openly-licensed effectively prevents academic libraries and non-profit research focused organizations to readily create a free and open social graph of scholarship (Shotton, 2018). Until the majority of citation metadata becomes openly licensed for re-use, funding agencies and academic institutions will continue to pay exorbitant costs for products such as Elsevier's SciVal and Clarivate Analytics' Incites to determine what the value their researchers output and how they rank compared to other organizations. 


\section{Responding to the Current Academic Publishing Environment}

The second part of this paper is a direct response to the first where I highlight some of the means by which open access and open science advocates are resisting enclosure. I call one particular strategy that appears to show the most promise, large (open) data and small tools.

Through a tremendous amount of labour, institutional repositories have been able to make a small but significant amount of research (and the metadata about said research) both readily available to readers and licensed for reuse by others (Larivière \& Sugimoto, 2018). Non-profit organizations such as Our Research have consolidated these efforts by harvesting the metadata and open access status of these works and have created apps such as Unpaywall that use this data to direct readers to open access copies at the point of need. While it has been recognized that additional investment in the open scholarship ecosystem is necessary to expand this shared commons (Maxwell et al., 2019), we should pay particular attention to the amount of value that the two-person company of Our Research has been able to share and leverage (Else, 2018).

We should also be reminded that no consortium of libraries has a development budget that can out-muscle the publisher Elsevier, which has a net revenue of $\$ 9.8$ billion (2018; MIT Libraries, 2019). In response, scholarly communications teams are following the lead of Our Research and are working towards more lean and agile responses. Instead of building competing products, scholarly communication librarians, researchers, and other open access advocates now facilitate workflows using free, open-source tools such as Zotero and OpenRefine. Not unlike Archivmatica, which is a compilation of open source tools rather than a single product (Preforma, n.d.), there is an increased use of small command-line programs supplemented with Python and $\mathrm{R}$ libraries as evidenced by a growing number of shared Juypter Notebooks and Github libraries. Examples of this work will be showcased in the presentation, such as Scholia, the work of a three-person team of open science advocates that turns open data on scholarship into open linked data.

\section{Closing Thoughts}

At the moment, it is up to individual decisions that will lead us collectively to a more or less open scholarly landscape. This includes the choice to create an ORCiD profile in addition to (or instead of) a Scopus ResearcherID, for that information can be allowed to be copied re-used widely. Researchers should be aware of other strategies such as publishing one's illustrations and figures on your personal website under a creative commons license before publishing in a more restrictively-licensed research journal.

Let us be reminded that authors and libraries historically have preceded publishers. The story of the greatest library of all-the Library of Alexandria — was built, in part, by the making of copies of the scrolls that were confiscated from ships that entered the city's ports (Philips, 2010). The solution to keeping the commons open is to make multiple copies of it readily available.

Copying is always already a crucial aspect of our ability to articulate ourselves and our world. Language functions mimetically, and therefore discourse, ideology, self-expression, community are also mimetic. The same is true for the university. As Kate Eichhorn has argued in her study of copy shops around the University of Toronto, historically universities have always relied on those who provide copying services (this was true even in medieval times), whether legal or not.

Open/Technology in Education, Society, and Scholarship Association Conference Proceedings: 2021, Vol. 1(1) 1-4 
Put simply: there is no university without copying, since the university's mandate is itself disseminative mimesis (Boon, 2010, p. 242).

\section{Open Researcher and Contributor Identifier (ORCID)}

Mita Williams (iD https://orcid.org/0000-0001-7816-6965

\section{Conflict of Interest}

The author does not declare any conflict of interest.

\section{References}

Boon, M. (2010). In praise of copying. Harvard University Press.

Bridle, J. (2018). New Dark Age: Technology and the end of the future. Verso.

Else, H. (2018). How Unpaywall is transforming open science. Nature, 560(7718), 290-291. https://doi.org/10.1038/d41586-018-05968-3

Elsevier. (n.d.). Article sharing. https://www.elsevier.com/about/policies/sharing

Hinchliffe, L. J. (2019, March 1). Springer Nature syndicates content to ResearchGate. Scholarly Kitchen. https://scholarlykitchen.sspnet.org/2019/03/01/springer-naturesyndicates-content-to-researchgate/

Kramer, B., \& Bosman, J. (2016). Innovations in scholarly communication-Global survey on research tool usage. F1000Research, 5. https://doi.org/10.12688/f1000research.8414.1

Larivière, V., \& Sugimoto, C. R. (2018). Do authors comply when funders enforce open access to research? Nature, 562(7728), 483-486. https://doi.org/10.1038/d41586-018-07101-w

Maxwell, J. W., Hanson, E., Desai, L., Tiampo, C., O’Donnell, K., Ketheeswaran, A., Sun, M., Walter, E., \& Michelle, E. (2019, July). Mind the gap: A Landscape analysis of open source publishing tools and platforms. https://mindthegap.pubpub.org/

MIT Libraries. (2019, August 8). Elsevier fact sheet . https://libraries.mit.edu/scholarly/publishing/elsevier-fact-sheet/

Philips, H. (2010). The Great Library of Alexandria? Library Philosophy and Practice. https://digitalcommons.unl.edu/libphilprac/417

Posada, A., \& Chen, G. (2018). Inequality in knowledge production: The integration of academic infrastructure by big publishers. In L. Chan \& P. Mounier (Eds.), ELPUB 2018. https://doi.org/10.4000/proceedings.elpub.2018.30

Preforma. (n.d.). ARCHIVEMATICA. http://www.preforma-project.eu/archivematica.html

Price, G. (n.d.). ResearchGate granted U.S. Patent 10,282,424: "Linking documents using citations." infoDOCKET. https://www.infodocket.com/2019/05/07/researchgate-grantedu-s-patent-10282424-linking-documents-using-citations/

Schonfeld, R. C. (2019, December 3). Publishers announce a major new service to plug leakage. Scholarly Kitchen. https://scholarlykitchen.sspnet.org/2019/12/03/publishersannounce-plug-leakage/

Shotton, D. (2018). Funders should mandate open citations. Nature, 553(7687), 129-129. https://doi.org/10.1038/d41586-018-00104-7 